\title{
Review Article \\ Recycling versus Long-Term Storage of Nuclear Fuel: Economic Factors
}

\author{
B. Yolanda Moratilla Soria, Maria Uris Mas, Mathilde Estadieu, \\ Ainhoa Villar Lejarreta, and David Echevarria-López
} Universidad P. Comillas, ETSI (ICAI), Cátedra Rafael Mariño de Nuevas Tecnologías Energéticas, C/ Alberto Aguilera 23,
28015 Madrid, Spain

Correspondence should be addressed to B. Yolanda Moratilla Soria; ymoratilla@upcomillas.es

Received 13 December 2012; Revised 4 June 2013; Accepted 4 June 2013

Academic Editor: Candido Pereira

Copyright (C) 2013 B. Yolanda Moratilla Soria et al. This is an open access article distributed under the Creative Commons Attribution License, which permits unrestricted use, distribution, and reproduction in any medium, provided the original work is properly cited.

\begin{abstract}
The objective of the present study is to compare the associated costs of long-term storage of spent nuclear fuel—open cycle strategywith the associated cost of reprocessing and recycling strategy of spent fuel-closed cycle strategy-based on the current international studies. The analysis presents cost trends for both strategies. Also, to point out the fact that the total cost of spent nuclear fuel management (open cycle) is impossible to establish at present, while the related costs of the closed cycle are stable and known, averting uncertainties.
\end{abstract}

\section{Introduction}

1.1. State-of-the-Art. The current demand of resources and the increasing and intensive energy consumption per capita have motivated development policies of efficient forms of energy in the electric generation area. Nuclear and renewable energies play an important role in our energy future, helping to meet increasing electricity demand while at the same time decreasing carbon dioxide emissions [1]. As a nation develops its nuclear strategies, it must consider various aspects of nuclear energy such as sustainability, environmental friendliness, proliferation resistance, economics, and technologies and evaluate all the possible nuclear fuel cycle options [2-5].

Over the last decade, numerous assessments [6-14] have been developed in order to compare the two main spent fuel strategies: strategy one which is the disposal of spent nuclear fuel generated by nuclear power plants operating in a "oncethrough" fuel cycle in a deep geologic repository and strategy two which is closing the fuel cycle by reprocessing and recycling the spent nuclear fuel. One of the latest economic analyses carried out by Ko and Gao [15] shows that the difference in the fuel cycle costs between recycling strategy and "once-through" strategy is negligible. Therefore, other factors such as the intangible asset play important roles in determining the future nuclear fuel cycle options. De Roo and Parsons [16] have developed the first methodology to calculate the levelized cost of electricity extended to the reprocessing strategy.

Högselius [17] gives an explanation of why the world's nuclear power countries differ from each other with respect to their spent nuclear fuel (SNF) policies according to the five main broad explanatory factors: military ambitions and nonproliferation, technological culture, political culture and civil society, geological conditions, and energy policy.

The UK's nuclear energy landscape assessment [18] also considers the long-term strategy for storage, reprocessing or disposal of UK's current and future nuclear fuel and waste stockpiles.

Studies developed in US will need to compare each of the fuel cycle options regarding sustainability, proliferation risk, commercial viability, waste management, and energy security in order to define the future of nuclear power [19-21]. Recktenwald and Deinert [22] present a probabilistic analysis of the costs to build, operate, and decommission the facilities that would be required to reprocess all US spent nuclear fuel generated over a one-hundred-year time frame, showing 
discounting results in life-cycle costs decreasing as recycling is delayed.

Although China's nuclear power industry is relatively young and the management of its spent nuclear fuel is not yet a concern, China's commitment to nuclear energy and its rapid pace of development require detailed analyses of its future spent fuel management policies. Zhou $[23,24]$ in his studies concluded that China can and should maintain a reprocessing operation to meet its $\mathrm{R} \& \mathrm{D}$ activities before its fast reactor program is further developed.

Suchitra [25], in his paper, assesses the economics of reprocessing in India and the cost of producing plutonium for the fast breeder reactor program, suggesting a cost of reprocessing approximately $\$ 600 / \mathrm{kg} \mathrm{HM}$ with assumptions favorable to reprocessing and close to $\$ 675 / \mathrm{kg} \mathrm{HM}$ under other assumptions.

The purpose of this report is to analyze and compare the results obtained from studies conducted by the Nuclear Energy Agency (NEA) for the Organization for Economic Co-operation and Development (OECD) in 1985 [6] subsequently updated in 1991, by the Massachusetts Institute of Technology (MIT) in 2003 [9], by the Boston Consulting Group (BCG) in 2006 [11], by De Roo and Parsons in 2011 [16], and by the Electric Power Research Institute (EPRI) in 2010 [12].

1.2. Used Fuel Management: General Aspects. Currently, the production of electricity from nuclear sources is based on the "fission" of $\mathrm{U}_{235}$ and, in lesser proportions, $\mathrm{Pu}_{239}$. In order to better understand this process, we will review some of the concepts and milestones regarding this technology, albeit in a very simplified manner, as this paper focuses on economic aspects of management.

1.2.1. What Is Used Fuel? In light water reactor nuclear power plants such as those found in Western countries, fission is produced in the previously mentioned atoms. This fission generates energy which is then used to heat water from a cooling cycle which evaporates and enters into a steam generator, thereby producing electricity. With this "nuclear fuel fission" reaction, new isotopes, products of the fission, are created in the nuclear reactor. At the same time, transuranic elements are transmuted by neutron capture into actinides which are capable of fission and energy generation.

As the U-235 nuclei continue the fission process, the amount of fissile material decreases while the fission and actinide products increase until reaching the point in which the chain reaction is no longer maintained in the reactor. To prevent this, fuel elements must be substituted for the other nonirradiated elements.

The used fuel found in the light water reactors consists of uranium oxide enriched in isotope 235 by a variable percentage of approximately 5\%. As previously indicated, some reactors use a mixture of enriched uranium and $\mathrm{Pu}$ 239 , which is produced in the reactor. Natural uranium, which is extracted from mines, only contains roughly $0.7 \%$ of U-235. The natural uranium is concentrated and converted into uranium hexafluoride. This compound is enriched by the necessary quantity of U-235 in order to reach the required percentage for the reactor.

After its use in the reactor, the fuel is then discharged. The exact composition of the used fuel depends on the amount of time it was in the reactor as well as on the neutron flux levels to which it was subjected. In schematic terms, nuclear fuel evolution can be represented as shown in Figure 1. Initially, it consists of U-235 (fissile) and U-238 (fertile, as it can be transmuted to $\mathrm{Pu}-239$ ). Once the fuels are removed from the reactor, a fraction of the initial U-235 remains and another fissile element has formed, $\mathrm{Pu}-239$. Both of these elements can be reused. In some countries, and for several years now, mixed uranium and plutonium fuels have been used, made from already used and reprocessed fuels (MOX fuels through mixed oxides), as well as Enriched Reprocessed Uranium (ERU) fuels, made of depleted uranium, the result of reprocessing (RepU-(Reprocessed Uranium)).

The evolution of fuel during irradiation in a reactor can be simplified in the following manner.

(i) The content of U-235, initially at $4 \%$, is reduced to $1 \%$.

(ii) The $3 \%$ of U-235 is converted into fission products (FP).

(iii) The $3 \%$ of U-238 is converted principally into Pu and, in lesser amounts, into other transuranic elements, minor actinides (MA).

(iv) A portion of the $\mathrm{Pu}$ has fissioned, increasing the quantity of fission products.

When the fuel elements are removed from the reactor, they are deposited into specially prepared pools which are located in the nuclear plant complex in order to release any residual thermal energy and to reduce their level of radioactivity for later treatment, be it in the final waste deposit site or in reprocessing for subsequent recycling.

1.2.2. Long-Term Used Fuel Management Options. For very long-term management of these elements, transmutation or fission technologies in accelerator-assisted systems or Generation IV fast reactors are considered. In this way, the radiotoxicity of the radioactive waste, in a period of onehundred years, will be reduced to levels existing naturally, due to the naturally radioactive elements of which they are composed.

These technologies are still in a developmental phase and have yet to be applied to an industrial scale. As previously mentioned, there are two existing alternatives for the definitive management of used fuel elements in a final stage. The elements can be safely stored in stable deep geological repositories $(D G R)$ so as to be contained and isolated from the environment and humans for centuries, while their radiotoxicity declines. This is the open cycle. Or, on the contrary, processes can be applied to allow for the uranium and plutonium to be removed and recycled, isolating the fission products and other minor actinides in a glass matrix. This, the closed cycle, in removing plutonium from the final waste product, results in a reasonable level of radiotoxicity. In both cases, the fuel elements are specially prepared and 


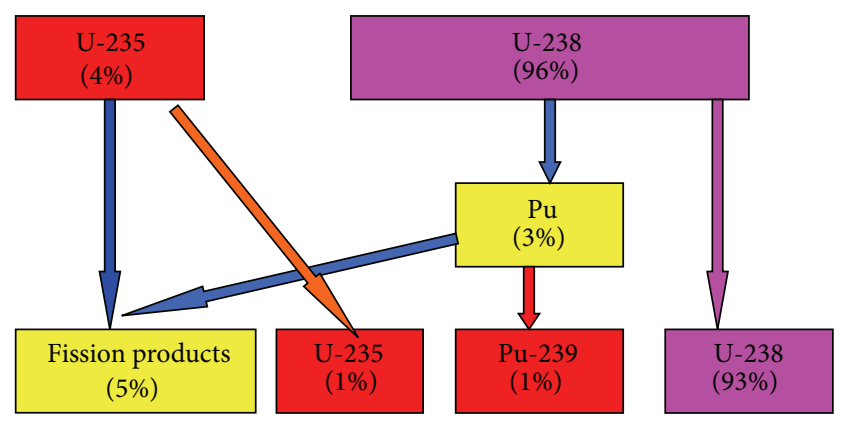

Figure 1: Evolution of fuel from a nuclear reactor during an operating cycle.

temporarily stored in an appropriately treated site until the final management phase is initiated.

Two countries, Sweden and Finland, have definitively adopted the open cycle and are in the preconstruction phase of the geological repositories for fuel element storage in copper capsules with granite subsoil.

One of the principles of any waste management policy in developed countries is that of reducing, recycling, and reusing waste products. The application of this principle to radioactive waste requires separating the unused and/or produced fissile material, reusing the material in new fuels, as previously described, and reducing the highly active waste to minor actinides-fission products that are obtained in a reactor by uranium transmutation.

In the closed cycle option, as it is currently practiced, after cooling the used fuel through chemical and mechanical processes, the recyclable uranium and plutonium materials are separated, so as to be used in the fabrication of new ERU fuels, and MOX fuels (Mixed Oxides with uranium and plutonium), which can be used in conventional reactors. This recycled fuel offers savings of up to $25 \%$ in natural uranium [9]. As stated in the MIT report, "recycle of the plutonium reduces uranium fuel demand by only $15 \%$ and recycle of the uranium reduces uranium fuel demand by only $10 \%$." This is confirmed by AREVA's experience in the reprocessing of used fuel, where from 7 to 9 spent nuclear fuels (depending on the characteristics of spent UOx and burn up), 1 ERU and 1 MOX are fabricated. The nonreusable materials, both the fission products and the structural portions of the fuel element are the final waste products. When the fuel material is separated after the shearing, the metal parts become insoluble, so they can be compacted and the nuclear materials can be separated easier. The fission products and the minor actinides, making up some $90 \%$ of the radioactivity of the used fuel, are vitrified. The structural parts are crushed and compacted by a press, which enables to reduce its volume before being packed into stainless steel containers, so as to optimize their final management in the geological repositories. The companies that carry out this reprocessing confirm their ability to divide the volume of final waste by a factor of 5 and the toxicity by a factor of 10 , since the final waste product is free of the highly radiotoxic plutonium [26].

Those countries with reprocessing facilities are France, Russia, the United Kingdom, Japan, India, Pakistan, and, most recently, China. However, many other countries reprocess or have reprocessed part of their used fuel, although they do not have their own facilities, and they recycle or have recycled in their reactors. This is the case in Holland, a country which has reprocessed the total amount of its used fuel and has a centralized storage facility where they store reprocessed vitrified waste instead of used fuel.

Today, some 90,000 tons of used fuels (of the 290,000 tons discharged) from commercial reactors have been reprocessed [27]. MOX fuel is currently used in various countries across the world, particularly in European countries such as France, Germany, and Switzerland, in order to feed their light water nuclear reactors. Some 5,500 elements from MOX and ERU fuels have been charged in reactors worldwide [28].

\subsubsection{Closed or Open Cycle: A Choice Based on Energy Strate-} gies, Both Worldwide and in Spain. It is noteworthy to mention that the large majority of countries [29] have delayed the decision regarding the direct deposit of fuel as waste or recycled material and currently choose to store the used fuel in a temporary manner, awaiting its final destination. Spain is among these countries. In the past, some of the used fuel was reprocessed in the Santa Maria de Garoña, José Cabrera and Vandellós I plants, but currently, as stated in the Radioactive waste management plan (VI General Radioactive Waste Plan, GRWP [30]) — guidelines followed by ENRESA, the radioactive waste management organism in Spain-it is possible to partially reprocess abroad, which would be a "potential alternative scenario, even though this option cannot be considered to be exclusively a question of waste management, but rather, and depending on the quantity to be reprocessed, it is a policy issue of energy supply" [30]. Therefore, used fuel is currently considered to be highly active waste.

In Spain, some 2,000 tons of low- and medium-activity waste are produced annually along with some 160 tons of high activity waste. The eight operating nuclear reactors in Spain produced $21 \%$ of the electric energy that was consumed in Spain in 2011 and generated 95\% of this waste.

The absence of a definitive decision regarding the final destination of the used fuel and the delay in the creation of programs for deep geological repositories (DGR) have created the need for temporary solutions: increased capacities of the used fuel pools in the plants, construction of temporary storage sites near the plants, and, key for Spanish used-fuel management: a project to create a temporary centralized storage facility.

On December 30, 2011, the Spanish Council of Ministers approved a resolution whereby the municipality of Villar de Cañas (Castilla-La Mancha) was chosen as site of the temporary centralized storage facility for highly active nuclear waste and used fuel generated by the Spanish nuclear energy industry. Planned for a total period of sixty years, this site will store all of the used fuel generated in the eight reactors in Spain for forty years-some 6,700 tons of used fuel.

\section{Methodology}

The methodology followed to evaluate the values presented in the analyzed reports consists of the comparison of three 
concepts: the cost of uranium ore, the storage costs in deep geological repositories (DGR), and the cost of reprocessing the spent nuclear fuel. In order to work with comparable values, the criteria used for each cost has been as follows.

(i) Cost of uranium ore: over the past years, the uranium price has shown an increasing trend of $\$ 36 / \mathrm{lb} . \mathrm{U}_{3} \mathrm{O}_{8}$ reaching a maximum of almost $\$ 45 / \mathrm{lb}_{3} \mathrm{O}_{8}$ in 19751980 , and a second maximum of $\$ 136 / 1 \mathrm{~b} \mathrm{U}_{3} \mathrm{O}_{8}$ in 2007. This trend is shown in Figure 2.

(ii) DGR cost: the storage cost for spent nuclear fuel has been considered to be the cost per kilogram of heavy metal (kg HM) stored. Transport costs, combustible costs for transport, encapsulating costs, and uranium credits are not included.

(iii) Reprocessing cost: the cost of reprocessing the spent nuclear fuel includes reprocessing costs per se and the cost of vitrification.

In each study, a sensitivity analysis was carried out for the different variables, with the DGR costs as well as the reprocessing costs having nominal values within a range with upper and lower margins. The criterion used to determine the nominal value is described in detail in each report.

Table 1 shows the nominal values from each report, shown in dollars from the year of the study.

In order to make an appropriate cost comparison, the prices have been updated to the year 2011 using the following conversion equation:

$$
\frac{C_{2}}{C_{1}}=\frac{I_{2}}{I_{1}}
$$

with $C_{2}$ and $I_{2}$ being, respectively, the cost and the cost index to be estimated at the current time and $C_{1}$ and $I_{1}$ being the cost of each study and the cost index of the corresponding year. For this purpose, the chemical engineering plant cost index (CEPI) has been used.

\section{Results}

3.1. Economic Values. Table 2 has been obtained updating the values from Table 1 in accordance with the CEPI price indexes, to the year 2011. Although the paper by De Roo was published in 2011, it was carried out with $\$ 2007$, so the costs have been updated also to 2011 .

In order to analyze the values updated to the year 2011 for each report, a graphic evaluation of the DGR costs versus time has been created as shown in Figure 3.

The differences between the DGP costs trend published by the OCDE and BCG (growing trend) and the MIT and De Roo (decreasing trend) are remarkable. As stated in an OCDE study dedicated to geologic disposal, 1993, "Permanent geologic disposal of spent fuel and HLW has not been demonstrated, and approaches to waste disposal vary considerably from country to country, making cost estimates highly uncertain" [31]. And Sweden, quoted in a Harvard study of 2003, released, for example, a cost estimate in 1998 of $\$ 300-\$ 350 \mathrm{~kg} \mathrm{HM}$ [32]. It is noteworthy that all of the estimates show an increasing trend in time, including this last Swedish cost, except from the report of the MIT, which is significantly higher, although it should be more comparable with De Roo, since both reports use as a reference the Yucca Mountain storage for their DGR cost calculations.

A second analysis carried out to compare the trend for the reprocessing cost is presented in Figure 4.

The reprocessing costs show a decreasing trend since 1985 except in the MIT and De Roo study.

The decreasing trend could be explained by the technical and economic improvements of the reprocessing technology, which have turned it into a mature technology and consequently could have led to a cost decrease. This also will apply to the technology of the DGR, in a medium-long term, although this should not happen in the next years, due to the high level of uncertainties of estimates based on design studies, as stated in the OCDE study of 1993 [31].

3.1.1. Noneconomic Values. Other nonquantifiable economic factors should be considered to carry out a comparison between both spent fuel strategies; open cycle with direct disposal and closed cycle with reprocessing of the spent fuel. As stated in the OCDE study on the DGR of 1993, the disposal of spent fuel or reprocessing waste is expected to be a highly controversial political issue in most countries, and the social and political issues will inevitably affect the costs [31].

There, reprocessing and recycling of the spent fuel seems to be the most sustainable strategy mainly because of the reduction of total volume of final waste to dispose.

The nonquantifiable economic factors are the intangibles assets. The most noteworthy intangible assets are

(i) Reprocessing and recycling strategies save up to $25 \%$ uranium ore, as explained before, reducing the volume of nuclear waste to disposal by a factor of 5 as well as the thermal load.

(ii) The relative radiotoxicity and the radioactive decay are considered to be intangibles assets, difficult to evaluate quantitatively yet offering an undisputed added value compared to the open cycle, from a public opinion viewpoint. The relative radio toxicity level is reduced by a factor of 10 , as can be observed in Figure 5.

(iii) The separation of plutonium 239 from spent nuclear fuel in the reprocessing phase and its later recycling into MOX avoids the nuclear proliferation. The plutonium of the spent MOX fuel is less appropriate for use in nuclear weapons.

(iv) The vitrified waste products, including the products obtained in the fission, are initially beta-gamma emitters, so the radioactive emission capacity is reduced in about some five-hundred years.

An opinion survey carried out in seven countries in 2010 showed that almost $80 \%$ of the respondents would advise their governments to begin recycling used nuclear fuel immediately, by using existing industrial solutions [33]. 


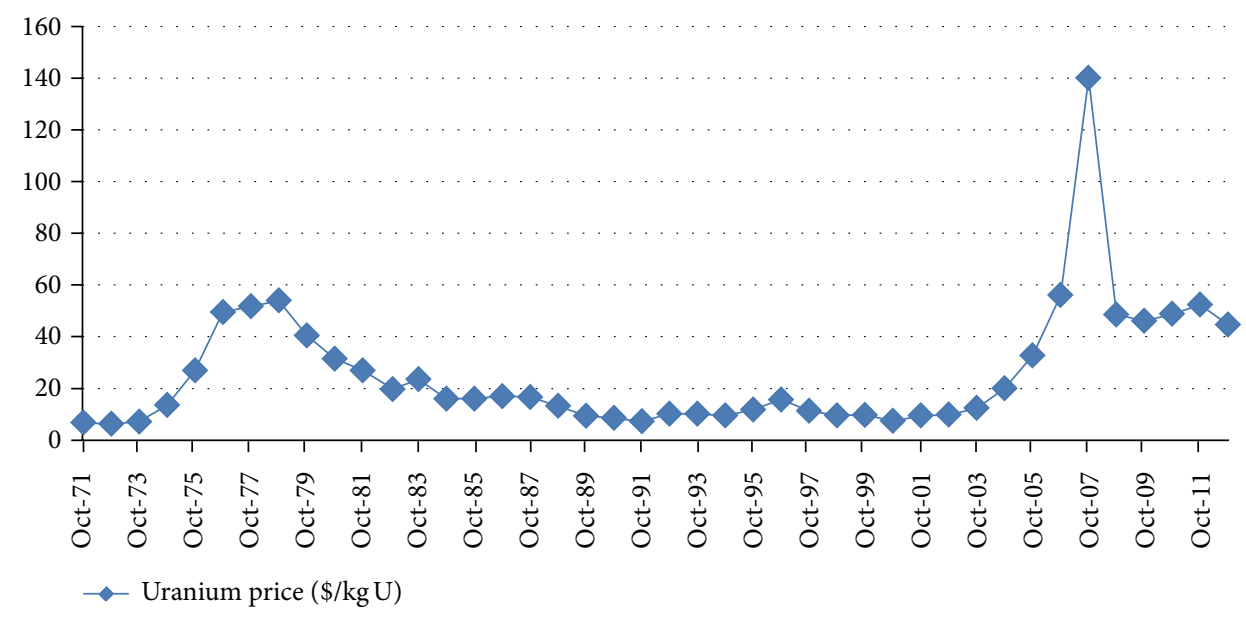

FIgURE 2: Uranium price chart.

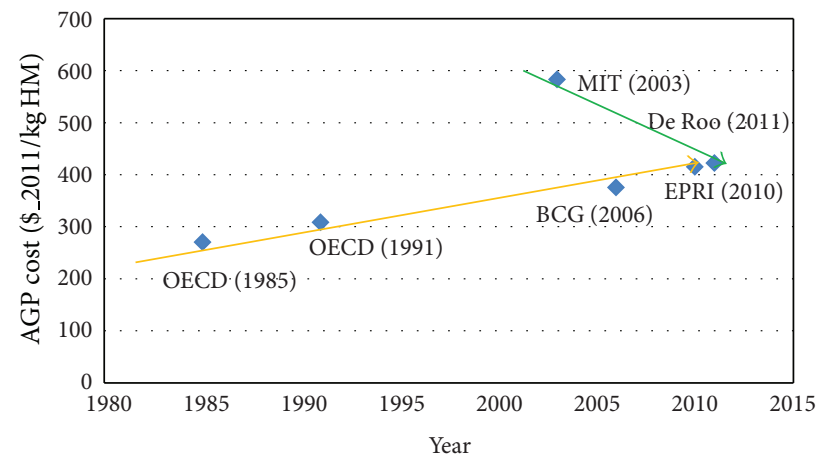

FIGURE 3: DGR costs trend.

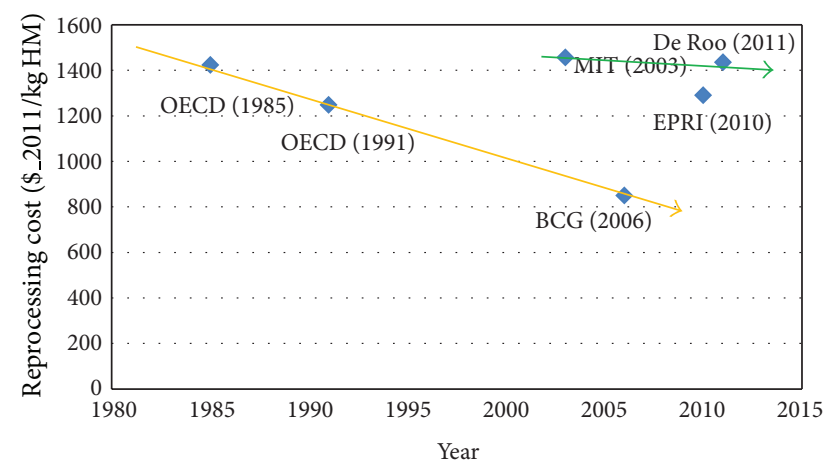

FIGURE 4: Reprocessing cost trend.

3.1.2. Spent Fuel Management Strategy in Spain. It is also necessary to consider the current instability of the Spanish legal landscape as exemplified by the draft bill on tax measures related to environmental and sustainable energy, placing new taxes on the value of electric energy generation, the production of spent nuclear fuel and the radioactive waste resulting from nuclear energy generation as well as on the storage of spent nuclear fuel, and radioactive waste in centralized interim storage facility (ATC).

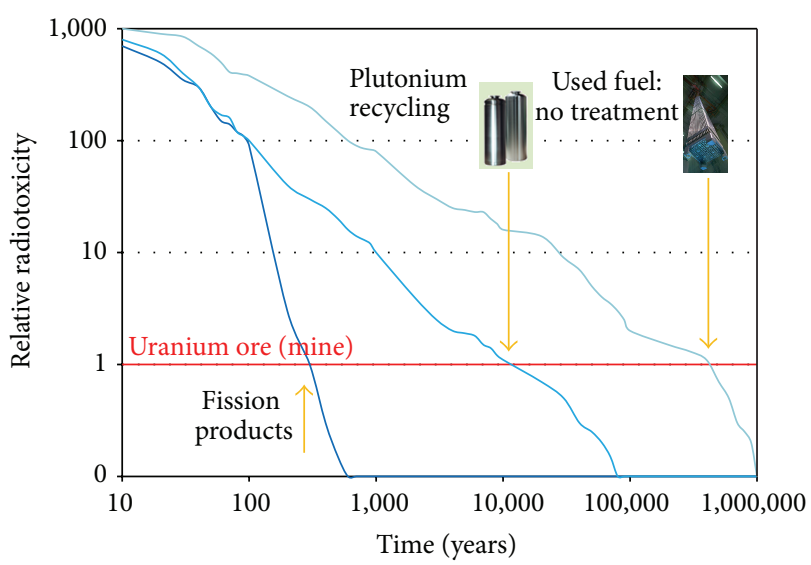

FIgure 5: Radioactive decay. Source: adapted from Commissariat à l'énergie atomique 2013 [34].

Article 22 from Chapter III of the Spanish Bill on the Storage of High Level Waste and Spent Fuel distinguishes between spent fuel, whose taxable base is per kilogram of heavy metal, and other highly active waste, whose taxable base is per cubic meters.

(i) Spent nuclear fuel is taxed per kilogram of heavy metal stored, at a rate of $70 € / \mathrm{kg} \mathrm{HM}$.

(ii) Radioactive waste will be taxed per cubic meter, at a rate of $30,000 € / \mathrm{m}^{3}$.

It should be noted that this distinction carries with it consequences for reprocessed Spanish used fuel: the tax applied to spent fuel will no longer be applied to the content of heavy metal in the stored fuel elements but rather, only to the 5th part: vitrified and compacted waste returned to Spain after being reprocessed-recycled, changing the taxable base and the applicable rate.

Also noteworthy is the fact that in the 6th GRWP, calculations for DGR cost have not been explicitly included as such. The base has been calculated up until 2070; however, 
TABLE 1: Results from the studies.

\begin{tabular}{|c|c|c|c|c|c|c|}
\hline & $\begin{array}{l}\text { NEA-OECD } \\
(1985)[6]\end{array}$ & $\begin{array}{l}\text { NEA-OECD } \\
\text { (1991) [6] }\end{array}$ & MIT (2003) [9] & $\begin{array}{c}\text { BCG (2006) } \\
{[11]}\end{array}$ & $\begin{array}{c}\text { EPRI (2010) } \\
{[12]}\end{array}$ & $\begin{array}{c}\text { De Roo and } \\
\text { Parsons (2011) } \\
{[16]}\end{array}$ \\
\hline $\begin{array}{l}\text { Uranium price } \\
(\$ / \mathrm{kg} \mathrm{U})\end{array}$ & 83.2 & 50 & 30 & 68.8 & 260 & 80 \\
\hline $\begin{array}{l}\text { DGR cost } \\
(\$ / \mathrm{kg} H \mathrm{HM})\end{array}$ & 150 & 190 & 400 & 320 & 354 & 470 \\
\hline $\begin{array}{l}\text { Reprocessing cost } \\
(\$ / \mathrm{kg} \mathrm{HM})\end{array}$ & 790 & 770 & 1100 & 725 & 1100 & 1600 \\
\hline
\end{tabular}

TABLE 2: Results obtained from studies updated to 2011.

\begin{tabular}{|c|c|c|c|c|c|c|}
\hline & $\begin{array}{l}\text { NEA-OECD } \\
(1985)[6]\end{array}$ & $\begin{array}{l}\text { NEA-OECD } \\
\text { (1991) [6] }\end{array}$ & MIT (2003) [9] & $\begin{array}{c}\text { BCG }(2006) \\
{[11]}\end{array}$ & $\begin{array}{c}\text { EPRI (2010) } \\
{[12]}\end{array}$ & $\begin{array}{c}\text { De Roo and } \\
\text { Parsons (2011) } \\
{[16]}\end{array}$ \\
\hline $\begin{array}{l}\text { Uranium price } \\
\left(\$_{2011} / \mathrm{kg} \mathrm{U}\right)\end{array}$ & 149.8 & 81 & 43.7 & 80.6 & 276.5 & 89 \\
\hline $\begin{array}{l}\text { DGR cost } \\
\left(\$_{2011} / \mathrm{kg} \mathrm{HM}\right)\end{array}$ & 270.1 & 308.1 & 582.8 & 375.2 & 376.5 & 422 \\
\hline $\begin{array}{l}\text { Reprocessing cost } \\
\left(\$_{2011} / \mathrm{kg} \mathrm{HM}\right)\end{array}$ & 1422.4 & 1248.3 & 1458 & 1602.6 & 1783.6 & 1169.7 \\
\hline
\end{tabular}

many management and long-term costs for the construction of a DGR or for solutions such as transmutation have not been included while the implied costs for the DGR may have been underestimated, as can be deduced from the increase between the calculations of ENRESA between 1999 and 2006: the 6th GRWP acknowledged a 40\% costs increase between the 2006 estimates and the last calculations made in 1999 for the interim storage [30]. ENRESA explains this increase by a better and more precise understanding of the design of the foreseen facility. This difference is most likely to be foreseen as well in the case of the DGR, taking in account to the previous observations. However, this increase could be minor in case of disposal of vitrified and compacted waste, as would be the case in the closed cycle: the management of a used fuel, 100-year old, from the time of its discharge to its ultimate storage for 60 years in a temporary centralized storage facility, requires various operations, perhaps complex ones, that would be unnecessary in the case of vitrified and compacted waste that was designated, from its production, to be stored for thousands of years.

\section{Conclusions}

When it comes to comparing global costs for the management of spent nuclear fuel, the studies analyzed in this report face considerable uncertainties due to two principle reasons: first, because this is a very long-term management issue, these theoretical and forward-looking studies must make several estimations based on the costs of certain processes that have yet to be fully developed and implemented, for a period of time in which costs could potentially change and be influenced by a variety of factors that are not currently known or quantifiable. Also, there are uncertainties related to these same characteristics of the potential management options: the overall cost of the open cycle as it is impacted by the estimated cost of certain solutions that have yet to be implemented on an industrial level, and in the closed cycle, as it deals with costs of commercial services that depend upon offers and are subjected to the policies of the serviceproviding company. As a consequence, the results of these comparative studies depend considerably upon the hypothesis which is chosen by the research team, explaining in great part why there are conflicting findings. However, we have determined that, in all of the studies, two factors decisively impact the overall cost of each option: the estimated cost of the deep geological repositories (DGR) in the open cycle and the reprocessing costs in the closed cycle. According to the information accumulated from all of the reports consulted, it was determined that while the costs associated with the DGR in the open cycle increase with time, due to the increasing uncertainties associated with the technology and its associated costs, the economic data related to the use of reprocessing decreases, precisely for the opposite reason, as this is a mature technology being consistently improved, with experience and $R \& D$ resulting in the lower prices. Controlled future back-end costs will significant decrease back-end's financial uncertainties going along recycling option thanks to mature industry. On the contrary, there is an important financial risk for used fuel disposal for which encapsulation is still under development and economic evaluation is usually revised upwards. Limitation of financial risk is related to final disposal along with recycling thanks to the volume, heat load, and radiotoxicity reduction and final waste conditioning in standard canisters.

This conclusion leads us to recall the advantage offered by the reprocessing-recycling option in the decrease of uncertainties, as it deals with known, stable and applied costs in a horizon that is closer to the production of used fuel. 
It is also important to recall that the choice between direct deposal and recycling of spent nuclear fuel does not depend solely on a vision of industrial management responding to the criterion of economic profitability but also depends on a global energy policy. Thus, the decision must take into account logic behind environmental and social sustainability. Here, the intangible assets of reprocessing and subsequent recycling offer a more sustainable solution that greatly reduces the volume and toxicity of the final waste product that is to be stored-the legacy that is to be inherited by our future generations, and principal preoccupation of our fellow citizens.

\section{References}

[1] P. L. Joskow and J. E. Parsons, "The economic future of nuclear power," Daedalus, vol. 138, no. 4, pp. 45-59, 2009.

[2] B. H. Park, F. Gao, E.-H. Kwon, and W. I. Ko, "Comparative study of different nuclear fuel cycle options: quantitative analysis on material flow," Energy Policy, vol. 39, no. 11, pp. 6916-6924, 2011.

[3] R. Natarajan and B. Raj, "Fast reactor fuel reprocessing technology: successes and challenges," in Proceedings of the 2nd International Conference on Asian Nuclear Prospects (ANUP '10), pp. 414-420, October 2010.

[4] L. Borges Silverio and W. D. Q. Lamas, "An analysis of development and research on spent nuclear fuel reprocessing," Energy Policy, vol. 39, no. 1, pp. 281-289, 2011.

[5] M. Kotschenreuther, P. Valanju, and S. Mahajan, "Reprocessing free nuclear fuel production via fusion fission hybrids," Fusion Engineering and Design, vol. 87, no. 4, pp. 303-317, 2012.

[6] OECD/NEA, The Economics of the Nuclear Fuel Cycle, OECD, Paris, France, 1994.

[7] F. N. Von Hippel, "Plutonium and reprocessing of spent nuclear fuel," Science, vol. 293, no. 5539, pp. 2397-2398, 2001.

[8] M. Bunn, S. Fetter, J. P. Holdren, and B. van der Zwaan, "The Economics of Reprocessing versus Direct Disposal of Spent Nuclear Fuel," Harvard Kennedy School. Project on Managing the Atom.

[9] The Future of Nuclear Power, An Interdisciplinary MIT study, Massachusetts Institute of Technology, 2003.

[10] T. P. Lagus, "Reprocessing of spent nuclear fuel: a policy analysis," Journal of Engineering and Public Policy, vol. 9, pp. 127, 2005.

[11] BCG, Economic Assessment of Used Nuclear Fuel Management in the United States, 2006.

[12] EPRI, "An Economic Analysis of Select Fuel Cycles Using the Steady-State Analysis Model for Advanced Fuel Cycles Schemes (SMAFS)," 1015387, Technical Update, EPRI Project Manager J. Hamel, 2007.

[13] Y. Du and J. E. Parsons, "Update on the Cost of Nuclear Power," Working Paper 09-004, Center for Energy and Environmental Policy Research, 2009.

[14] The Future of Nuclear Power, An Interdisciplinary MIT study, Massachusetts Institute of Technology, 2011.

[15] W. Ko and F. Gao, "Economic analysis of different nuclear fuel cycle options," Science and Technology of Nuclear Installations, vol. 2012, Article ID 293467, 10 pages, 2012.

[16] G. De Roo and J. E. Parsons, "A methodology for calculating the levelized cost of electricity in nuclear power systems with fuel recycling," Energy Economics, vol. 33, no. 5, pp. 826-839, 2011.
[17] P. Högselius, "Spent nuclear fuel policies in historical perspective: an international comparison," Energy Policy, vol. 37, no. 1, pp. 254-263, 2009.

[18] S. Widder, "Benefits and concerns of a closed nuclear fuel cycle," Journal of Renewable and Sustainable Energy, vol. 2, no. 6, Article ID 062801, 2010.

[19] "A low carbon nuclear future: economic assessment of nuclear materials and spent nuclear fuel management in the UK," Smith School of Enterprise and the Environment University of Oxford, 2011.

[20] W. M. Nutt, Z. Duncan, and T. Cotton, "Prioritization criteria for the selection of used nuclear fuel for recycling," in Proceedings of the WM Conference, Phoenix, Ariz, USA, 2011.

[21] E. A. Schneider, M. R. Deinert, and K. B. Cady, "Cost analysis of the US spent nuclear fuel reprocessing facility," Energy Economics, vol. 31, no. 5, pp. 627-634, 2009.

[22] G. D. Recktenwald and M. R. Deinert, "Cost probability analysis of reprocessing spent nuclear fuel in the US," Energy Economics, vol. 34, pp. 1873-1881, 2012.

[23] Y. Zhou, "Why is China going nuclear?" Energy Policy, vol. 38, no. 7, pp. 3755-3762, 2010.

[24] Y. Zhou, "China's spent nuclear fuel management: current practices and future strategies," Energy Policy, vol. 39, no. 7, pp. 4360-4369, 2011.

[25] M. V. Ramana and J. Y. Suchitra, "Costing plutonium: economics of reprocessing in India," International Journal of Global Energy Issues, vol. 27, no. 4, pp. 454-471, 2007.

[26] M. Chiguer, J.-L. Casabianca, and J.-P. Gros, "Recycling as an option of Used Nuclear Fuel Management Strategy for Europe".

[27] World nuclear Info, http://www.world-nuclear.org/info/inf69 .html\#R5.

[28] M. Chiguer, J.-L. Casabianca, and J.-P. Gros, "Recycling as an option of Used Nuclear Fuel Management Strategy for Europe".

[29] International Atomic Energy Agency, Country nuclear fuel profiles 2005.

[30] 6th GRWP;C.II.1.3 Strategic action lines.

[31] The Cost of High-Level Waste Disposal in Geological Repositories. An Analysis of Factors Affecting Cost Estimates. Nuclear Energy Agency. Organization for economic Co-Operation and Development, 1993.

[32] M. Bunn, J. P. Holdren, S. Fetter, and B. Van der Zwaan, "The economics of reprocessing versus direct disposal of spent nuclear fuel," Supported by the U.S. Department of Energy (DOE).

[33] http://www.tns-sofres.com/_assets/files/2010.02.22-areva.pdf.

[34] Monographies DEN: une monographie de la Direction de l'énergie nucléaire Commissariat à l'énergie atomique, L'énergie nucléaire du futur: quelles recherches pour quels objectifs? (2005). 


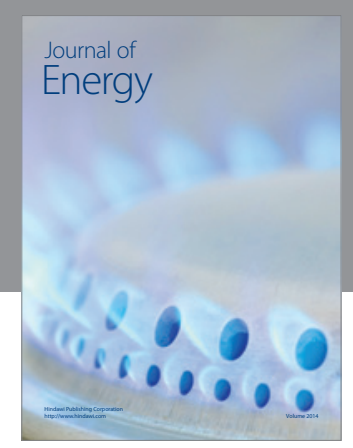

Journal of

Industrial Engineering
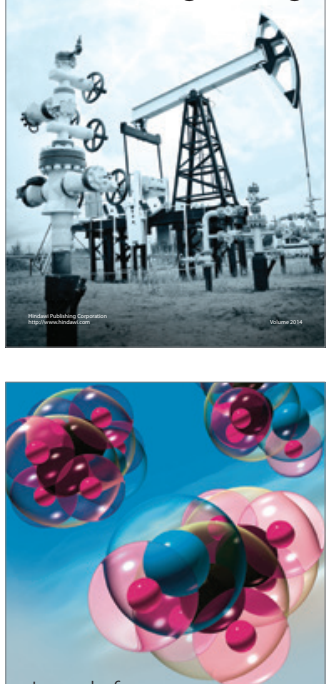

Fuels
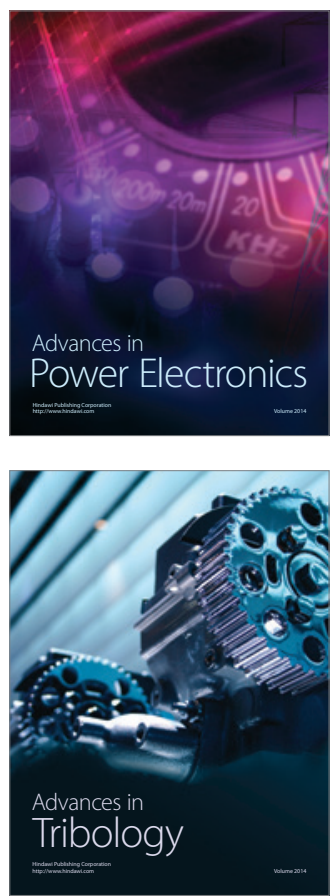

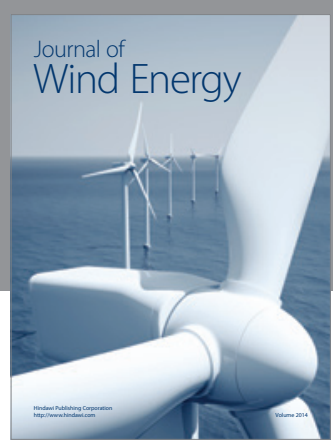

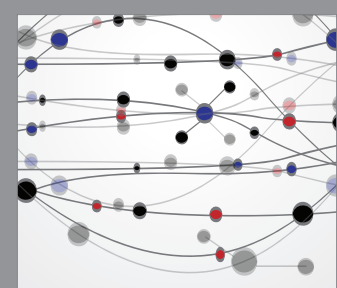

The Scientific World Journal

Submit your manuscripts at http://www.hindawi.com

Journal of

Structures
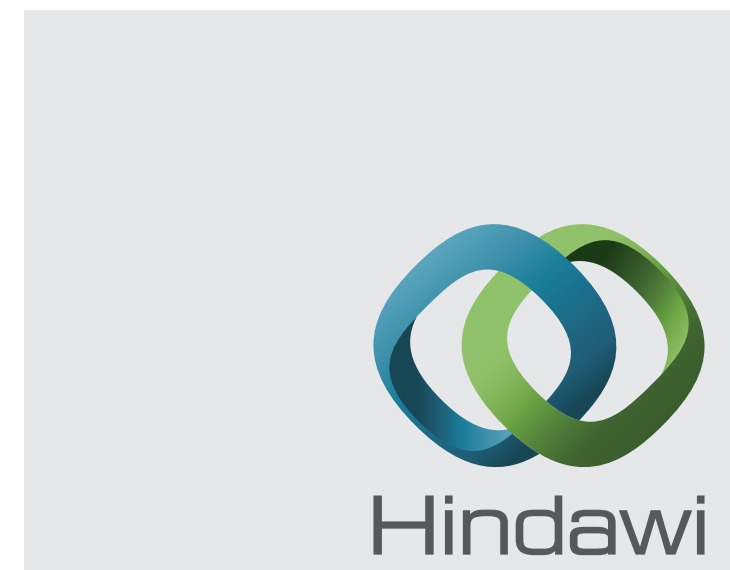

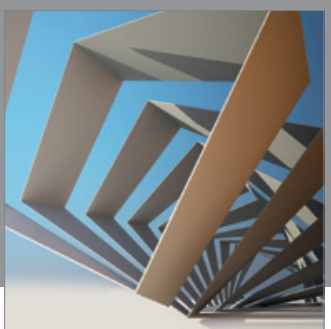

Rotating

Machinery
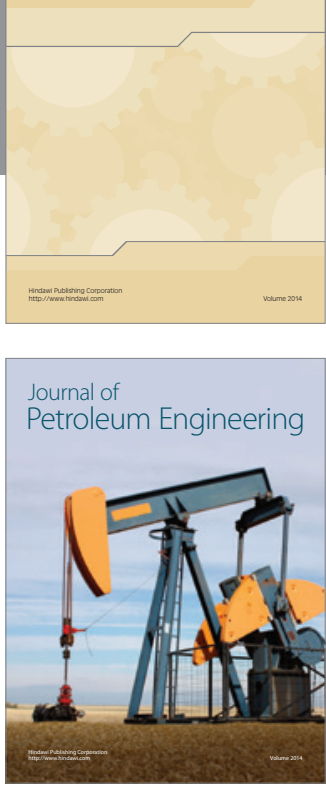

Journal of

Solar Energy
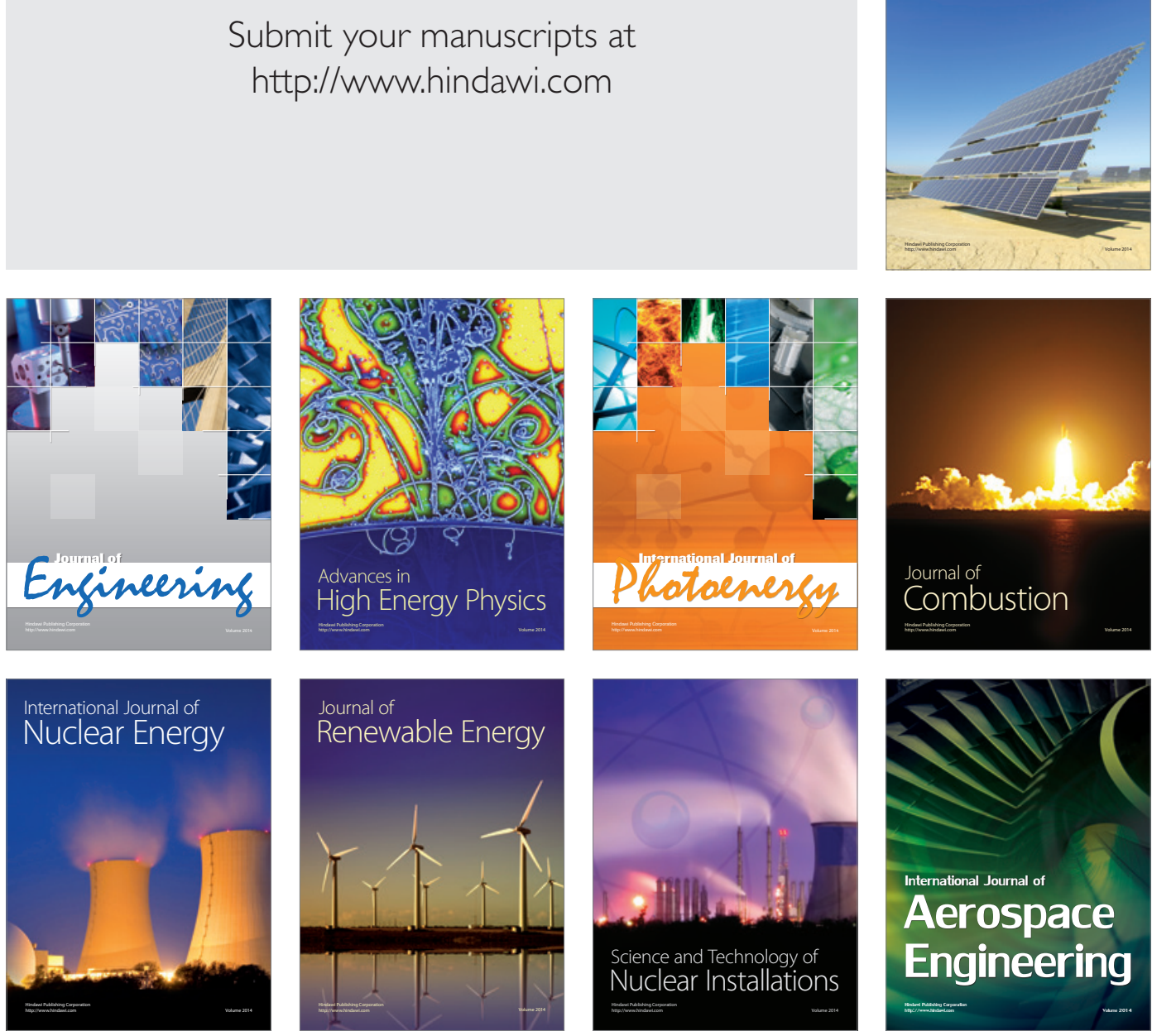